\title{
INFLUENCING STRENGTH OF GENDER AND LOCUS OF CONTROL ON MARITAL ASSERTION: A SAMPLE OF NIGERIAN GRADUATE POPULATION
}

\author{
${ }^{1}$ ESTHER, UKWUOMA ORJI, ** \\ 08060599414 \\ ${ }^{2}$ EWAH-OTU BEATRICE* \\ 08061650127 \\ ${ }^{3}$ FELICIA OGUDU CHUKWU OKO* \\ 08050521420
}

$1 \& 2 \& 3$ Department Of Social Sciences, Akanu Ibiam Federal Polytechnic, Unwana.

https://doi.org/10.37602/IJSSMR.2020.3308

\begin{abstract}
Many marriages today are often experiencing difficulty in handling interpersonal problem which requires that each person should express him/herself in an assertive way, thus, passivity and aggressive communication became the nearest choice of communication. Expressing statement in an assertive way tend to reduce quarrel, misunderstanding, and confusion among couples. The question of whether gender and locus of control could enhance marital assertion is the concern of this study. Researching on that will give an impetus to the solution to solving the marital problem and improving marital adjustment. One hundred and five (105) married graduate couples (comprising 210 participants; 105 men and 105 women) purposefully selected from Ebonyi State metropolis participated in this study. They were administered both Assertive Behaviour Assessment Scale and Nowicki-Strickland Internal-External Locus of Control Scale. The ANOVA result showed a statistically significant difference in marital assertion between internally-oriented and externally-oriented participants. It, however, revealed no statistically significant difference in Marital assertion between men and women participants. It was concluded that locus of control should be considered a very important factor in psychosocial intervention to enhance marital assertion.
\end{abstract}

Keywords: Gender, External, Internal locus of control, marital assertion

\subsection{INTRODUCTION}

Marriage is viewed as a union between a man and a woman who are joined together by social rules and custom (Kocyigit, 2017). The fact that each person in this union has a different developmental milestone comprising both genetic and environmental make-up is quite enough to give a big difference in each person's behaviour. Many marriages today are often experiencing difficulty in handling interpersonal problem which requires that each person should express him/her self in an assertive way, thus, passivity and aggressive communication became the best-chosen choice. This negative choice of communication chosen may often lead to the rate of divorce, separation, and unhappy home found around 


\section{International Journal of Social Sciences and Management Review}

Volume: 03, Issue: 03 "May - June 2020"

ISSN 2582-0176

countries (Elizerbeth, Richard, Anna, \& Tim; 2018). Assertiveness according to Onyeizugbo, (2001) is the ability of an individual to communicate ones' needs, desires, and feelings, in an honest manner, without undue anxiety and aggression. Sheinov, (2020) refers to it as an individual's ability to communicate while protecting his or her rights in a self-assured pattern, maintaining dignity, without violating other people's rights. As, marriage is a phenomenon which requires a long-term and healthy relationship with positive emotion (Askari, Kamo, \& Shokoul, 2015), it often needs this ingredient of assertiveness that could promote its longevity and happiness and adjustment, Onyeizugbo, (2001), hence, separation and divorce have never be done without some amount of pain, cost and disappointment (Kocyigit, 2017). The marital assertion is a positive psychological construct that stands between passivity and aggressive communication. Studies on marital happiness, marital problem and adjustment have evidently studied those variables suspected to promote a happy home, reduce the marital problem and improve marital adjustment (Onyeizugbo, 2001; Robert, Fred, Alan, \& Marvarene, 2014; Elizerbeth, et. al.,2018; Kocyigit, 2017; Ascari, et. al. 2015), assertiveness has never been neglected. Onyeizugbo, (2001) studied the relationship between assertiveness and marital adjustment and found a strong positive correlation between assertiveness and marital adjustment. Although, there is scanty current literature on marital assertion and its influencing factors. This study tends to replace this vacuum by studying the influencing strength of gender and locus of control on marital assertion.

\subsection{Marital Assertion}

Marital assertion is a socially appropriate pattern of relating to each other that reflect honesty and genuine expression of thoughts and feeling. It is commonly associated with the ability to start, continue and maintain rewarding marital communication thus, holding the respect and right of each other. The assertion in the other hand, is a behavioural characteristic according to (Izzet, 2019), that improves effective communication skill among married couples. Expressing statement in an assertive way may tend to reduce quarrel, misunderstanding, and confusion among couples. This is because, it allows individuals to consciously and respectfully respond to others and also express his/her feelings, thought, desires and wants whether it is negative or positive in a socially appropriate time and in a genuine way. Just as Makus, (2018) put it up that, the assertion is a justified speech according to the belief about the issue at hand. The behavioural theory suggested that ones failure to develop assertiveness is due to learned anxiety responses (Wolpe, 1958,1973). This theory was supported by Learning theorist who also asserts that assertion or non-assertion is acquired through observing significant models (Bandura, 1978). Therefore, lack of marital assertion could be a failure to master or learn assertiveness skills, just as Onyeizugbo, (2003) moved it forward that, the correct pattern of marital assertion depend mostly on the skill with which it adheres to social norms of the environment. Galassi, Delo, Galassi, and Bastien (1974) also stated that assertive people are communicative, free-spirited, secure, self-assured, and able to influence and guide others. Thus, if assertiveness is vital in engendering the above personal attributes, it may equally raise happy home which every individual is clamouring.

Conversely, standing on the literature reviewed above, high assertive husband or wife would be more communicative and may tend to raise a long-term relationship. In other hand, that husband or wife who fails to learn and act assertively may have had some personal characteristics that might limit him or her to assertive competent. Invariably, those that act assertively may have had some personal characteristics that might have improved their 


\section{International Journal of Social Sciences and Management Review}

ISSN 2582-0176

marital assertion. The recognition of internal and external locus of control as one of the personal characteristics that could seriously exert much influence on marital assertion is the concern of this study. Researching on these variables may help to identify those married couple that are assertive and the attribute of their personal characteristic (locus of control and gender), and those that are not assertive and the attribute of their personal characteristics (locus of control and gender). And generally, the research will cover the vacuum created for long period about these variables to the research community. It will also give an impetus to the solution on solving marital problem and improving marital adjustment. Thus, the following research question is raised:

1) Will internal and external locus of control stand as an influencing factor of marital assertion?

2) Will gender difference stand as an influencing factor of marital assertion? Locus of Control and Marital Assertion

\subsection{Locus of Control and Marital Assertion}

Locus of control is a personality characteristic describing how individual believe the control of their live is located (Nowicki, \& Strickland; 1973). In another word, it gives an explanation on how one is convinced and make referral attribution about the causes of events that occur in his/her lives either by fate. luck, or gods. Okechi, Nwankwo, Nkiru, and Chinenye, (2013) put it as how people attribute determinant of live events and expectation. An individual may either have an internal or external locus of control. Those with an internal locus of control do believe that a live event that happens to them is out of their personal ability and control, while individuals with an external locus of control do attribute that, the causes of everything that happens to them is out of luck, a quirk of fate, or gods' wishes. Invariably, internals believe that personal factor exerts influence on the event of their daily live goal, while external believes that outside factor has much influence on the causes of things that occur to their daily live goal.

Locus of control as a personality attribute is a variable suggested in this study that could lay much influence on marital assertion. This is because, internal who believes that they have control over their daily live goal and circumstances; take initiatives; seek a positive relationship, and may positively adopt changes in their married lives that could grant a healthy happy home. It may as well be strongly associated with marital assertion. This is because they can decide to master or lean assertiveness skill as a method of communication that could serve as means of creating happy home. Conversely, external individuals who believed their lives are controlled by outside factor may feel dis-empowered to master or acquire assertiveness skill. Nevertheless, it could be that assertiveness skill could be found in them, which may also be an attributes used by them and thereby leaving other thing to fate. Attribution theory explained it well that internals attribute the causes of success or failure to their own ability, while externals attribute the causes of success and failure to outside factors. The ability to learn assertiveness effectively may be successfully achieved by internals who believed they can change a situation. Externals may have low interest on the value of assertiveness thereby having nothing to do with it (Lim, 2007).

\subsection{Gender, Locus of Control and Assertion}




\section{International Journal of Social Sciences and Management Review}

Volume: 03, Issue: 03 “May - June 2020"

ISSN 2582-0176

Gender role and sex differences are suspected to exert some amount of potential influence between men and women relating the association between locus of control and assertiveness. This expected gender roles may lead one to assume that gender dynamics would contribute to differences in locus of control and marital assertion. Also. the dynamics between women's personal characteristics and behavioural characteristics can be found in some culture much quite different to that of men. This could be because of the assumption that woman's assertive manner sometimes is not duly accepted by some culture. Most contemporary Nigerian culture often offer such assumption in marital relationship, that women should behave passively, while men should have the more authoritative attribute. This could be a suspected barrier that may contribute to lack of women assertion, and because there is scant empirical evidence to support this assumption. This study try to examine that in this recent world of women education and global era of computer, science and technology, the assertive competent among men and women, and whether there would be a difference between men and women on their assertiveness level. There are very scanty recent literature on the relationship between internal and external locus of control on assertion and in relation with gender differences. The few literature at hand tried to collaborate these variables with another socio-economic and cultural variable. For instance, Askari, Kamo, Shokouh, (2015) studied the interrelationships among locus of control, sexual satisfaction and marital satisfaction, and found out that locus of control and marital satisfaction significantly related to each other. They also found out that, the more the internal, the greater the marital satisfaction. For the fact that marital assertion is a positive psychological construct leading to healthy behaviour, it could also be classified as a component of marital satisfaction. Thus, locus of control could also exert a positive influence on marital assertion. A study by Sheinov, (2020) on locus of control, assertiveness and other personal characteristics variables revealed a positive bilateral correlation between assertiveness and external locus of control. The same study, in a group made up of equal numbers of men and women showed a positive correlation between assertiveness and the internal locus of control. Also, Robert, et. al, (2014) examined the relation between assertiveness and marital adjustment and no relation was found between assertion and marital adjustment for the total group of 187 randomly selected married graduate students. The same study, by sex, a positive relation was found between these two factors for males, but not for females. In their second study, 15 students who completed one of two five-week assertion training workshops significantly increased their levels of assertive behavior relative to a control group, but no significant difference was found in marital adjustment between groups. Okechi, et. al, (2013), studied the role of Locus of control on assertive behavior of adolescent. The null hypothesis which stated that, there will be no statistical significant influence of locus of control on assertive behavior of adolescent; with 80 participants drawn randomly from Abakaliki local government area Nigeria, was rejected. Also, the study of Williams and Stout (2007) on the effect of high and low assertiveness on locus of control, reported that highly assertive individuals were found to be more internally controlled than were individuals low in assertiveness. With the above literature revealed so far, it could be said that, gender and locus of control may have something to offer on marital assertion. Thus, the following research hypothesis was raised:

1. There would be a statistically significant difference between participant with an internal locus of control and participant with an external locus of control on marital assertion.

2. There would be a statistically significant difference between men participant and women participant on marital assertion. 


\section{International Journal of Social Sciences and Management Review}

\subsection{The Present Study}

The present study examined the influencing strength of gender and locus of control on marital assertion. Two hundred and ten (210) married graduate couple drawn from Ebonyi state metropolis (105 men, and 105 women) aged 19 and 38 with mean age of 28.5 participated in the study. Participants were selected on a voluntary basis. Purposive sampling techniques were employed to select 210 married graduate couple population that participated in the study. Sampling was done on their various offices and residents.

\subsection{Instrument}

Nowicki-Strickland locus of control scale (N-SLCS), is one of the instruments used in this study. It is a 40 item inventory specifically used to assess the extent to which an individual has an internal or external locus of control (Nowicki, et. al, 1973). The item has two options; (Yes/No). The inventory included such specific item as " Do you think it's better to be smart than Lucky?" A client total score is the addition of the "Yes" and the "No" items correctly shaded. A score above the mean (30) indicate external locus of control while a score below the mean indicate the internal locus of control. The second instrument used was Assertive behaviour assessment scale (ABAS). It contains 18 items developed by Onyeizugbo (1998). The instrument was specifically used to measure the assertive behaviour of married people. It is a Likert-type scale ranged from 1(Always), to 5(Never). It included such specific item as "I am shy to speak up in a discussion". The highest score for an assertive item is five (5) while the lowest score is (1). The value assigned to each option depends on whether it measures assertiveness in the positive or negative direction. The numerical value attached to each item were summed giving rise to a cumulative score which was used for the analysis.

\subsection{Procedure}

The two instruments were distributed to the participants by the researchers. The NowickiStrickland locus of control scale (N-SLCS) was placed on top of Assertive behaviour assessment scale (ABAS) and attached together. Two pairs were given to each couple. Cooperation and informed consent were obtained. Participants were told that participating in the study was voluntary. Out of the 350 copies of a questionnaire distributed, 250 were returned, representing a return rate of $81 \%$. Forty couple copies of the questionnaire returned were discarded because they were incompletely filled and some had no gender indication, leaving a total of 210 that was used for data analysis.

\subsection{Design/Statistics}

The study was a cross-sectional survey design, employing two levels of locus of control (Internal and External) and two levels of gender (Men and Women). Analysis of variance (ANOVA) statistics was used to analyze the data.

\subsection{RESULTS}

Table 1: Mean and Standard Deviation scores of gender and their locus of control on the assertion 


\section{International Journal of Social Sciences and Management Review}

Volume: 03, Issue: 03 "May - June 2020"

ISSN 2582-0176

\begin{tabular}{|l|l|l|l|l|}
\hline Gender & Locus of control & Mean & Std. Deviation & N \\
\hline Men & Internals & 61.69 & 8.118 & 52 \\
& Externals & 50.42 & 10.18 & 53 \\
& Total & 56.00 & 10.779 & 105 \\
\hline Women & Internals & 60.42 & 7.84 & 50 \\
& Externals & 52.27 & 12.56 & 55 \\
& Total & 56.15 & 11.29 & 105 \\
\hline Total & Internals & 61.069 & 7.95 & 102 \\
& Externals & 51.36 & 11.44 & 108 \\
& Total & & 11.01 & 210 \\
\hline
\end{tabular}

The above table is the mean and standard deviation of gender in relation with internal and external locus of control on marital assertion. It showed that men who are internals are a bit smaller in number against those who are externals, but the internals showed slightly higher mean difference to those men who are externally oriented on marital assertion. Again, women who are internals are quite smaller in number against those women who are externals, but the internals showed remarkable higher mean difference with those women who are externally oriented on marital assertion.

Table 2: Summary of Mean score and standard deviation of gender and locus of control on assertion.

\begin{tabular}{llccc}
\hline Variable & & Mean & SD & N \\
\hline Gender: & Male & 56.00 & 10.78 & 105 \\
& Female & 56.15 & 11.29 & 105 \\
Locus of Control: & Internal & 61.06 & 7.97 & 102 \\
& External & 50.36 & 11.44 & 108
\end{tabular}

The table shows that the mean score of women participant (56.15) is slightly higher than that of men participants (56.00) on assertion. Also, participants with an internal locus of control had a higher mean score (61.06) than those who were external (50.36) on assertion. A twoway ANOVA was performed to determine if the observed differences among the groups were significant (see Table 3 below).

Table 3: ANOVA summary Table showing the effects of Gender x Locus of Control on Assertion

\begin{tabular}{lcclll}
\hline Source of variance & Sum of square & df & Mean square & F & Sig \\
\hline Gender (A) & 10.14 & 1 & 10.14 & .11 & $\mathrm{~ns}$ \\
Locus of control (B) & 4799.16 & 1 & 4799.16 & 49.98 & $* *$ \\
A x B & 89.70 & 1 & 89.70 & 93 & $\mathrm{~ns}$ \\
Error & 19398.38 & 202 & 96.03 & & \\
Total & 25350.78 & 209 & & &
\end{tabular}




\section{International Journal of Social Sciences and Management Review}

Volume: 03, Issue: 03 "May - June 2020"

ISSN 2582-0176

Key: $* *=$ Significant, $\mathrm{p}<.001$

$\mathrm{ns}=$ not significant

The results indicate that locus of control had a significant main effect on marital assertion, $\mathrm{F}$, $(1,202)=49.98, p<.001$. Hypothesis 1 was thereby accepted. On the contrary, gender had no significant main effect on marital assertion, $F(1,202)=.11$, ns. Hence, hypothesis 2 was rejected. The interaction effects for gender (A) and locus of control (B) was not significant, F, $(1,202)=.93$, ns.

\subsection{Implication of the Findings}

The result of this study clearly indicated that marital assertion is influenced by the locus of control. As can be observed from table 1, 2, and 3, a participant who is externals showed a statistically significant difference in their level of assertion with those who are internals, F, $(1,202)=49.98, \mathrm{p}<.001$. This indicated that the first hypothesis was accepted, which stated that, there would be a statistically significant difference in marital assertion between participant with an internal locus of control and participants with an external locus of control. The results obtained showed that locus of control influences marital assertion. This is in congruence with the results of some empirical studies reviewed in this study. A study by Williams, et. al, (2007) on the effect of high and low assertiveness on the locus of control revealed that assertive individuals were found more internally controlled than were individuals low in assertiveness. Our study confirmed this finding as to the participants who were more internals obtain higher mean score on assertion than those who are externally controlled despite their lesser number.

Surprisingly, the findings confirmed the study of Okechi, et. al, (2013) on the role of Locus of control on assertive behavior of adolescent, of which they rejected their null hypothesis which stated that there will be no statistically significant influence of locus of control on Assertive behavior of an adolescent. This present research found a significant influence of locus of control on assertiveness, thereby supporting their findings. This study also supported the findings of (Sheinov, 2020) who studied a group made up of equal numbers of men and women and observed a positive correlation between assertiveness and the internal locus of control.

It is observed through the findings that internals, who believe that every outcome of any event is as a result of their behavioural attributes, acted it out by expressing themselves assertively. Invariably, externals who do not attribute any good outcome of an event from their personal handwork may be less likely to act assertively, suggesting that attribution theory has been obeyed.

The result as shown in table 3 , reject the second hypothesis which stated that there would be a statistically significant difference between men and women on marital assertion F, $(1,202)=$ $.11 \mathrm{~ns}$. The finding indicates that, gender did not exert much influence on the marital assertion, though, a precise mean difference was found among women against men but it was not significant. This result is not in line with that of Robert, et. al, (2014) who examined the relation between assertiveness and marital adjustment for the total group of 187 randomly selected married graduate students. They observed by sex, that a positive relation was found between these two factors for males, but not for females. Even, Sheinov (2020) also observed 


\section{International Journal of Social Sciences and Management Review}

Volume: 03, Issue: 03 "May - June 2020"

ISSN 2582-0176

a positive correlation between assertiveness and the internal locus of control among men and women. The findings in this study suggest that gender does not influence marital assertion. This is to say that the pattern of correlation between different levels of assertiveness was similar in this study for both genders. Women, in particular, have often been viewed in contemporary Nigerian society as weak, hiding feelings and preferences, thereby adopting passivity in marital relationship. Though, the mean score of women on assertiveness showed slightly higher than that of men showing the impact of women education on their level of assertiveness, but it was not significant to conclude on that. This is a specific area of intervention that psychologists in assertive training progamme should look into. More active approach should also move into self- determination in mastering assertive skills among gender especially in a risky marital situation so to reduce (if not eradicate) the prevailing rate of divorce, separation and single parenting found around the country.

\subsection{Limitation of the Study}

The sample size used in this study could not be said to have been truly representative of married graduate couples population in Nigeria who are nonassertive regardless of locus of control. Sample procedures were designed to identify a larger sampling of married graduate couples population for this study but unfortunately, an adequate number was not secured.

An attempt by this research to find out the gender differences on marital assertion has been relatively unsuccessful. The implication is that gender differences could be linked to other societal factors and the age of the individual.

\subsection{Suggestion for Further Study}

Future research in this area should be closely linked with larger representative sample size. In future, the investigation should take into account equitable socio-economic status and age of the subjects. The study opened an important door for future research related to the influence of locus of control and gender on marital assertion.

Also, more longitudinal studies should investigate the relationship between age and marital assertion. While this study has begun to document current information on the influencing strength of locus of control and gender on marital assertion among married graduate couples in Ebonyi state metropolis, more research is needed to entrap the entire Nigerian population.

\subsection{SUMMARY}

The problem investigated was the influencing strength of locus of control and gender on marital assertion. External locus of control has been identified as one of the major problem leading to the low marital assertion. It was also identified that low marital assertion among couples today is dangerous in marital relationship. Observation has it today that married couple does have a serious problem on assertion leading to the rate of hidden separation and prevailing divorce cases found in Nigeria. The result of Onyeizugbo, (2001) on the relationship between assertiveness and marital adjustment, found a strong positive correlation between assertiveness and marital adjustment. The findings also show that people with an external locus of control feel dis-empowered to do anything about their lives living everything to fate. 


\section{International Journal of Social Sciences and Management Review}

Volume: 03, Issue: 03 "May - June 2020"

ISSN 2582-0176

\subsection{CONCLUSION}

The result showed that locus of control had a significant main effect on marital assertion. This really indicates that locus of control influences marital assertion in interpersonal relationships and precisely in marriage.

Although the sample size is small, the study did enable us to get an insight into the detrimental effect of external locus of control and marital assertion. It is anticipated by the researchers that though the use of awareness probes in the context of the effect of external locus of control among the married graduate couple, the larger sample size is hope to shed further light on this phenomenon.

The study showed that gender did not differ significantly in the assertiveness among graduate couples, suggesting that gender did not moderate the relationship between its differences and marital assertion.

\section{REFERENCES}

Askari, A., Kamo, V,. Shokouh, N. (2015). The interrelationship among locus of control, sexual satisfaction and marital satisfaction. Journal of Asian Scientific Research, 5(2): $60-72$

Bandura, A. (1978). Social learning theory. Journal of Communication, 28, 2-28.

Elizabeth, M. L., Richard, G. R., \& Anna, Z. (2018) Marital Happiness, Marital Status, Health, and Longevity. Journal of Happiness Studies https://doi.org/10.1007/s10902-018-0009-9

Galassi, J. P., DeLo, J. S., Galassi, M. D., \& Bastien, S. (1974). The College Self-Expression Scale: A measure of assertiveness. Behavior Therapy, 5(2), 165-171. doi:10.1016/S0005 7894(74)80131-0

Izzet, P. (2019). The effect of Assertiveness and Psycho-education program on increasing the assertiveness of university students. Sakarya University Journal of Education, 9 (1) 21- 32 .

Kocyigit, O. M. (2017). The Meaning of marriage according to University students; A phenomenological study. Educational Sciences. Theory and Practice, 17, 679-711.

Lim, H. (2007). Effects of attributions and task values on foreign language use anxiety. Journal of Education and Human Development, 1(2), 1-20.

Makus, k. (2018). The norm of assertion: Empirical data. Journal of cognition 177, 165 - 171.

Nowicki, S. \& Strickland, B. R. (1973). A locus of control scale for children. Journal of consulting and clinical psychology, 40. 148 - 154. 


\section{International Journal of Social Sciences and Management Review}

Volume: 03, Issue: 03 "May - June 2020"

ISSN 2582-0176

Okechi B.C., Nwankwo B.C., Nkiru E. O., \& Chinenye B. O (2013). Role Of Locus Of Control On Assertive Behavior Of Adolescents. International Journal of Health and Psychology Researchl.1, (1) pp.38-44

Onyeizugbo, E.U. (2001). Assertiveness: An Essential Ingredient in Marital Adjustment. Nigerian Journal of Social Sciences, 1, (1) 143 - 149.

Onyeizugbo, E. U. (2003). Effects of gender, age and education on assertiveness in a Nigerian sample. Psychology of Women Quarterly, 27, 12-16.

Onyeizugbo, E. U. (1998). The role of Gender, Age, and Educational Level in Assertiveness and Marital Adjustment. Unpublished M.Sc. theis, Department of Pyshcology, University of Nigeria, Nsukka.

Robert, A. R., Fred, P., Alan, H., \& Marvarene, O. (2014). Assertion and Marital Adjustment. National council on Family Relations, 29 (2), 249 - 253.

Sheinov, V. P. (2020). Assertiveness, Locus of Control, Affiliation and Vulnerability of Personality to Manipulation: Connection and Properties". EC Psychology and Psychiatry 9.(1) 01-07.

Wolpe, J. (1958). Psychotherapy by reciprocal inhibition. Stanford, CA: Stanford University Press.

Wolpe, J. (1973). The practice of behavior therapy. New York: Pergamon Press. 